\title{
Family history and risk of breast cancer: an analysis accounting for family structure
}

\author{
Hannah R. Brewer ${ }^{1,6} \cdot$ Michael E. Jones ${ }^{1} \cdot$ Minouk J. Schoemaker ${ }^{1}$. \\ Alan Ashworth ${ }^{2,3,4,5} \cdot$ Anthony J. Swerdlow ${ }^{1,2}$
}

Received: 25 May 2017/ Accepted: 29 May 2017/Published online: 3 June 2017

(c) The Author(s) 2017. This article is an open access publication

\begin{abstract}
Purpose Family history is an important risk factor for breast cancer incidence, but the parameters conventionally used to categorize it are based solely on numbers and/or ages of breast cancer cases in the family and take no account of the size and age-structure of the woman's family.

Methods Using data from the Generations Study, a cohort of over 113,000 women from the general UK population, we analyzed breast cancer risk in relation to first-degree family history using a family history score (FHS) that takes account of the expected number of family cases based on the family's age-structure and national cancer incidence rates.
\end{abstract}

Electronic supplementary material The online version of this article (doi:10.1007/s10549-017-4325-2) contains supplementary material, which is available to authorized users.

Hannah R. Brewer

Hannah.Brewer@icr.ac.uk

1 Division of Genetics and Epidemiology, The Institute of Cancer Research, London SW7 3RP, UK

2 Division of Breast Cancer Research, The Institute of Cancer Research, London SW7 3RP, UK

3 Breast Cancer Now Toby Robins Research Centre at The Institute of Cancer Research, London SW7 3RP, UK

4 Division of Molecular Pathology, The Institute of Cancer Research, London SW7 3RP, UK

5 Present Address: UCSF Helen Diller Family Comprehensive Cancer Center, San Francisco, CA 94158, USA

6 Division of Genetics and Epidemiology, The Institute of Cancer Research, Sir Richard Doll Building, Sutton, Surrey SM2 5NG, UK
Results Breast cancer risk increased significantly $\left(P_{\text {trend }}<0.0001\right)$ with greater FHS. There was a 3.5 -fold (95\% CI 2.56-4.79) range of risk between the lowest and highest FHS groups, whereas women who had two or more relatives with breast cancer, the strongest conventional familial risk factor, had a 2.5 -fold (95\% CI 1.83-3.47) increase in risk. Using likelihood ratio tests, the best model for determining breast cancer risk due to family history was that combining FHS and age of relative at diagnosis.

Conclusions A family history score based on expected as well as observed breast cancers in a family can give greater risk discrimination on breast cancer incidence than conventional parameters based solely on cases in affected relatives. Our modeling suggests that a yet stronger predictor of risk might be a combination of this score and age at diagnosis in relatives.

Keywords Breast cancer - Risk factors - Cohort study · Family history

$\begin{array}{ll}\text { Abbreviations } \\ \text { FHS } & \text { Family history score } \\ \text { GS } & \text { Generations study } \\ \text { HR } & \text { Hazard ratio } \\ \text { CI } & \text { Confidence interval } \\ \text { SIR } & \text { Standard incidence ratio } \\ \text { DCIS } & \text { Ductal carcinoma in situ }\end{array}$

\section{Introduction}

Breast cancer is the most common cancer in women and the leading cause of cancer-related deaths in women worldwide [1]. In addition to well-established reproductive and lifestyle risk factors such as early age at menarche and 
HRT intake, there is a strong risk in relation to family history of breast cancer, with a twofold increase in risk of developing the disease for women with breast cancer in their first-degree family, and a larger increase in risk among women with a first-degree relative diagnosed before age 50 compared with after age 50 years [2-4].

In assessing risk of breast cancer, the categorization of family history as a risk factor for breast cancer has ranged from presence or absence of a family history [5-13] to more specific descriptions of cases in the family such as the number, type, age at diagnosis (e.g., $\leq 45$ or $>45[14,15]$, or $\leq 50$ or $>50$ years $[11,14,16])$ of relatives who have had breast cancer [16-25], and a combination of the type of relative and age at diagnosis $[3,26]$. These methods did not consider, however, the number of female relatives, and the person-years they have lived through, by age and calendar period, i.e., the denominator of the family's risk. Women with many relatives who have reached older ages would be expected, for that reason alone, to have more relatives with breast cancer on average than those whose relatives are few and young. Cohort analyses of cardiovascular disease [26] and breast cancer mortality [27] have published risks in relation to a family history score that takes account of family structure. We therefore used data from the Generations Study, a cohort study of women in the UK, to analyze breast cancer incidence risks in relation to a family history score that takes account of the person-years at risk by age and calendar period, and the relatives' ages at breast cancer incidence, and hence the numbers of breast cancers expected in the family.

\section{Methods}

The Generations Study (GS) is a prospective cohort study that began recruiting women aged 16 or older from the general population of the United Kingdom in 2003 and now comprises over 113,000 women who completed an extensive questionnaire and provided consent [28]. The first follow-up questionnaire was sent to GS participants about two and a half years after their entry to the study and subsequent follow-up questionnaires at intervals of about three and a half years. The study was approved by the South East Multi-Centre Research Ethics Committee.

The current analytic cohort is based on women who joined the study between June 2003 and June 2012, inclusive. Participants who had been diagnosed with breast cancer before entering the study $(n=6604)$ or who reported that they did not know about their biological parents or siblings $(n=3905)$ were excluded. This left 103,738 participants who formed the analysis cohort. Breast cancers occurring in GS cohort participants were reported by these participants in their follow-up questionnaires, and later confirmed by cancer registry records, general practitioners, pathology records, or through 'flagging' at the National Health Service Central Registers (registers of England, Wales, and Scotland populations to which GS participants can be matched, and deaths and national cancer registrations then reported to authorized researchers).

\section{Statistical analysis}

\section{Assessment of breast cancer risk in families of participants}

Information about first-degree relatives' dates of birth, cancer history, and, for parents only, dates of death was provided by the participants in their recruitment questionnaire. There were 294,100 recorded first-degree female relatives of participants in this analysis cohort. For a small proportion of relatives, year of birth was not stated, or the stated year was impossible ( $n=12,458,4.2 \%$ of relatives), and for these women, year of birth was estimated (e.g., where birth year was unknown for mothers of participants, we assumed that the mother was older than the participant by the average age at childbirth in her generation). For analysis, we considered for each participant, all female full first-degree relatives as her 'family cohort' (i.e., half-sisters were excluded). Each relative in such a family cohort was considered to enter risk at her own date of birth and to leave risk at her year of breast cancer diagnosis, year of death (for mothers only), or the year the participant's recruitment questionnaire was received (i.e., the last date information was provided about the relative), whichever occurred earliest.

We calculated the expected number of breast cancers in each family cohort by multiplying the cumulative personyears in the family cohort, stratified by age and calendar year, by the corresponding national annual, age-specific breast cancer incidence rates, and then summing across all strata. Published national breast cancer incidence rates for England and Wales combined were only available from 1971 to 1998 . Rates from 1911 to 1970 were estimated by multiplying the age-specific breast cancer mortality rates in these years by the average age-specific ratio between published England and Wales incidence and mortality rates during 1971-1979. The average of the estimated incidence rates from 1911 to 1920 was used for years before 1911, when age-specific breast cancer mortality rates were not available. English national incidence rates were used for years after 1998 because combined England and Wales rates were not published after then. However, the difference will have been negligible since England contributes $94.6 \%$ of the combined population.

The total observed number of first primary breast cancers occurring in relatives in the family cohort was divided 
by the number of expected breast cancers, calculated as above, to produce a standardized incidence ratio (SIR) for that family. We will refer to this SIR as the 'Family History Score' (FHS).

Assessment of breast cancer risk in participants in relation to family history

We assessed risk of breast cancer in GS participants in relation to the FHS of their family, by calculating hazard ratios (HR) using Cox-proportional hazards regression with left truncation and right censoring, with age as the underlying time scale [29]. The FHS was ordered into six groups, and these groups were scored $0-5$ for trend tests. We also similarly assessed breast cancer risk in GS participants in relation to presence of a family history of breast cancer (yes/no), the number of relatives with breast cancer $(0,1$, $\geq 2$ ), the type of relative(s) with breast cancer (none, mother, sister, daughter, $\geq 2$ relatives), and the age of the youngest relative with breast cancer (none, $<45$, $\geq 45$ years). Relative risks of breast cancer were adjusted for age at menarche, benign breast disease, oral contraceptive use, parity, age at first birth, breastfeeding, age at menopause and menopausal status, hormone replacement therapy use, physical activity, pre- and post-menopausal body mass index, alcohol intake, smoking status, and socioeconomic status. For the HR calculations, participant entry to risk began on the date of completion of the recruitment questionnaire, and exit from risk was on the date the participant was diagnosed with breast cancer, date of last follow-up questionnaire, emigration, loss to followup, or death, whichever occurred earliest up to 30th August 2015.

To observe the impact of unknown vital status in sisters and daughters (i.e., of the assumption that they did not die before the other exit criteria had occurred), we conducted sensitivity analyses reducing the follow-up time (and hence expecteds) for sisters and daughters of GS participants in line with mortality rates in women of similar ages to the sisters and daughters without a history of breast cancer.

Because of the recruitment method [28], about $28 \%$ of participants have a first-degree relative who is also a GS participant, and in sensitivity analyses, we removed all participating relatives who joined the GS after the first participating relative.

For the main analyses, in situ diagnoses in participants were included together with invasive breast cancers, since ductal carcinoma in situ (DCIS) is widely considered to be a precursor of invasive breast cancer [30]. Women with such diagnoses are often treated with a mastectomy or lumpectomy and sometimes radiation and/or hormonal therapy [31]. Sensitivity analyses were also conducted, however, restricted to invasive breast cancers.
A likelihood ratio test was used to compare the contribution of the FHS to models with the presence of a family history of breast cancer (yes/no), the number of relatives with breast cancer $(0.1,>2)$, the type of relative(s) with breast cancer (non, mother, sister, daughter, $\geq 2$ relatives), and the age of the youngest relative with breast cancer (none, $<45, \geq 45$ ), i.e., measures of family history used in previous epidemiological studies [5-26]. All statistical tests were two sided, and analyses were done using Stata (version 14.0) [31].

\section{Results}

As of 30 August 2015, of the 103,738 GS participants, 1,474 were diagnosed with invasive breast cancer during follow-up and 259 with in situ diagnoses, giving a total of 1733 who reported breast cancer, with $99.8 \%$ confirmed from medical records. Follow-up questionnaires were completed by $96.3 \%$ of participants, and cancer status known from flagging for a further $1.7 \%$. The remaining participants had either died $(0.8 \%)$ or were lost to followup (1.2\%). Total follow-up was 627,944 person-years, an average of 6.1 years per cohort member.

Descriptive characteristics of women in the GS cohort are shown in Table 1. Almost half of the participants were aged 45-64 years $(47.4 \%)$ at recruitment, and $64.4 \%$ joined the study during 2006-2009. A slight majority (55.4\%) of women who developed breast cancer during follow-up were diagnosed before age 60 , with the overall mean age at diagnosis 53 years. There were 15,520 participants $(15 \%)$ who reported one or more relative(s) with a history of breast cancer at recruitment, with most relatives $(61.5 \%)$ diagnosed before age 60 and the overall mean age at diagnosis 57 years.

The relative risks of breast cancer in participants in relation to FHS are shown in Table 2. Eighty five percent of participants had no family member with breast cancer (i.e., FHS $=0$ ), $8 \%$ had non-zero scores up to 20 , and $7 \%$ had scores greater than this, with only $0.9 \%$ participants having a score $\geq 500$. Risk of breast cancer increased significantly as the FHS increased $\left(P_{\text {trend }}<0.0001\right)$. Participants in the highest FHS category had a relative risk of 3.50 (95\% CI 2.56-4.79; $P<0.0001)$ compared with those with no affected relatives.

The analysis in Table 2 was also conducted for risk of estrogen receptor-positive and estrogen receptor-negative breast cancers separately (Supplement Tables 1 and 2, respectively); there was a similar increase in risk of each as the FHS increased (FHS $\geq 100 \mathrm{HR}=3.1295 \%$ CI $2.14-4.55, P_{\text {trend }}<0.0001$; and FHS $\geq 100 \mathrm{HR}=3.61$ $95 \%$ CI $1.69-7.72, P_{\text {trend }}=0.0001$, respectively). In sensitivity analyses after reducing follow-up time in sisters 
Table 1 Descriptive characteristics of the Generations Study cohort members in the United Kingdom and their family history of breast cancer

\begin{tabular}{|c|c|c|}
\hline Characteristic & Number & Percent (\%) \\
\hline \multicolumn{3}{|c|}{ Participants in cohort } \\
\hline \multicolumn{3}{|c|}{ Age at entry to the study (years) } \\
\hline $16-24$ & 5591 & 5.4 \\
\hline $25-34$ & 17,430 & 16.8 \\
\hline $35-44$ & 22,872 & 22.0 \\
\hline $45-54$ & 24,668 & 23.8 \\
\hline $55-64$ & 24,459 & 23.6 \\
\hline $65-102$ & 8718 & 8.4 \\
\hline Total & 103,738 & 100.0 \\
\hline \multicolumn{3}{|l|}{ Year of entry } \\
\hline $2003-2005$ & 34,681 & 33.4 \\
\hline 2006-2009 & 66,756 & 64.4 \\
\hline 2010-2012 & 2301 & 2.2 \\
\hline Total & 103,738 & 100.00 \\
\hline \multicolumn{3}{|c|}{ Age at breast cancer diagnosis (years) } \\
\hline$<30$ & 7 & $0.4^{*}$ \\
\hline $30-44$ & 218 & 12.6 \\
\hline $45-59$ & 734 & 42.4 \\
\hline$\geq 60$ & 774 & 44.6 \\
\hline Total & 1733 & 100.0 \\
\hline \multicolumn{3}{|c|}{ Family history of breast cancer (no. of affected relatives) } \\
\hline 0 & 88,219 & 85.0 \\
\hline 1 & 14,750 & 14.2 \\
\hline 2 & 669 & 0.7 \\
\hline$\geq 3$ & 100 & 0.1 \\
\hline Total & 103,738 & 100.0 \\
\hline \multicolumn{3}{|c|}{ First-degree, female relatives of participants in cohort } \\
\hline \multicolumn{3}{|c|}{ Age at breast cancer diagnosis (years) } \\
\hline$<30$ & 149 & $0.9^{\mathrm{a}}$ \\
\hline $30-44$ & 2679 & 17.3 \\
\hline $45-59$ & 6716 & 43.3 \\
\hline$\geq 60$ & 5976 & 38.5 \\
\hline Total & 15,520 & 100.0 \\
\hline
\end{tabular}

* Percentages among those with breast cancer

${ }^{a}$ Percentages among relatives with breast cancer

and daughters without a history of breast cancer (see Methods), there was no change in relative risks of breast cancer $\quad(\mathrm{FHS} \geq 100 \mathrm{HR}=3.50,95 \%$ CI 2.56-4.79, $\left.P_{\text {trend }}<0.0001\right)$. When sensitivity analyses were conducted with only one participant proband included if more than one family member had joined the cohort (see Methods), there was still a similar increase in risk (FHS $\geq 100$ $\mathrm{HR}=3.3195 \%$ CI 2.38, 4.60, $\left.P_{\text {trend }}<0.0001\right)$. Analysis of invasive breast cancer only ( $n=1474$ cases) also showed a significant increasing trend $(\mathrm{FHS} \geq 100 \mathrm{HR}=3.09,95 \% \mathrm{CI}$ $\left.2.16-4.43, P_{\text {trend }}<0.0001\right)$. Omitting participants for whom date of birth was missing for any relatives had no material effect on the results.

Table 3 shows the adjusted relative risks of breast cancer in the GS based on several other methods of family history categorization. The relative risk of breast cancer in women with at least one first-degree female relative with breast cancer was increased compared with those without a family history $\quad(\mathrm{HR}=1.77, \quad 95 \%$ CI $\quad 1.58-1.97$, $P<0.0001$ ), while the breast cancer risk in participants with two or more relatives diagnosed with breast cancer more than doubled $(\mathrm{HR}=2.52$; 95\% CI 1.83-3.47; $P<0.0001)$. About $5 \%$ of participants with two or more relatives with breast cancer $(n=41)$ fell into the highest FHS score group, $10 \%$ into the FHS $50 \leq 100$ group $(n=72)$, and $85 \%(n=656)$ had a FHS below 50 .

Breast cancer risks were similar in participants with a mother only $(\mathrm{HR}=1.72 ; 95 \%$ CI $1.51-1.95 ; P<0.0001)$ or sister only $(\mathrm{HR}=1.73 ; 95 \%$ CI $1.40-2.13 ; P<0.0001)$ with breast cancer. Participants who reported a relative diagnosed with breast cancer before age 45 had a relative risk of 2.47 (95\% CI 2.01-3.04; $P<0.0001)$ which was significantly higher $(P<0.001)$ than those with an affected relative over age $45(\mathrm{HR}=1.6395 \%$ CI 1.45-1.84; $P<0.0001)$. None of these measures showed as great a risk discrimination as the FHS.

Likelihood ratio tests comparing models with and without the addition of the FHS to models with the measures of family history in Table 3 are shown in Table 4. The addition of the FHS gave a highly significant improvement to risk models containing binary family history $(P<0.001)$, the number of relatives with breast cancer $(P=0.001)$, the type of relative with breast cancer $(P<0.001)$, and the age of relative at breast cancer diagnosis $(P=0.01)$. Conversely, addition of binary family history or number of affected relatives to a model with FHS showed some evidence of significant improvement ( $P=0.04$ and $P=0.02$, respectively), but the addition of type of relative to the FHS showed no significant improvement $(P=0.35)$. The best combination of variables was one with relative age at breast cancer diagnosis and FHS, for which the addition of either in the presence of the other showed a highly significant improvement $(P=0.006$ and $P=0.01)$.

\section{Discussion}

Family history is an important breast cancer risk factor, and one that can cause considerable anxiety to women [32]. It is therefore important to measure the risk associated with it with as much discriminatory power as possible, both to improve overall risk prediction and for advice and information for women, especially those with affected relatives. 
Table 2 Relative risks of breast cancer in Generations Study members by family history score (FHS), adjusted for other breast cancer risk factors*

\begin{tabular}{|c|c|c|c|c|c|c|}
\hline Family History Score & No. of study participants & Person-years (1000) & No. of breast cancer cases & HR & $95 \% \mathrm{CI}$ & $P$ \\
\hline $0^{\mathrm{a}}$ & 88,219 & 534.5 & 1,301 & 1.00 & baseline & \\
\hline$<10$ & 3610 & 21.7 & 126 & 1.61 & $1.34,1.94$ & $<0.0001$ \\
\hline $10-<20$ & 4563 & 27.5 & 134 & 1.63 & $1.36,1.95$ & $<0.0001$ \\
\hline $20-<50$ & 4334 & 26.2 & 94 & 1.72 & $1.39,2.12$ & $<0.0001$ \\
\hline $50-<100$ & 1692 & 10.2 & 37 & 2.11 & $1.52,2.92$ & $<0.0001$ \\
\hline$\geq 100$ & 1320 & 7.9 & 41 & 3.50 & $2.56,4.79$ & $<0.0001$ \\
\hline Total & 103,738 & 627.9 & 1,733 & \multicolumn{3}{|c|}{ Test for trend $\mathrm{d}^{\mathrm{b}}:<0.0001$} \\
\hline
\end{tabular}

$H R$ Hazard Ratio from Cox regression using age as time scale, $C I$ Confidence interval

* Adjusted for age at menarche, benign breast disease, oral contraceptive use, parity, age at first birth, breastfeeding, age at menopause, hormone replacement therapy use, physical activity, pre- and post-menopausal body mass index, alcohol intake, smoking status, and socioeconomic status

${ }^{\text {a }}$ No history of breast cancer in first-degree female relatives

b Test for trend across six groups scored $0-5$

Table 3 Relative risks of breast cancer in Generations Study participants based on various commonly used categorizations of family history, adjusted for other breast cancer risk factors*

\begin{tabular}{|c|c|c|c|c|c|c|}
\hline Breast cancer in family ${ }^{a}$ & No. of study participants (\%) & Person-years (1000) & No. of breast cancer cases & HR & $95 \% \mathrm{CI}$ & $P$ \\
\hline \multicolumn{7}{|c|}{ Diagnosis of breast cancer in relative } \\
\hline No & $88,219(85.0)$ & 534.5 & 1,301 & 1.00 & baseline & \\
\hline Yes & $15,519(15.0)$ & 93.4 & 432 & 1.77 & $1.58,1.97$ & $<0.0001$ \\
\hline \multicolumn{7}{|c|}{ No. of relatives with breast cancer } \\
\hline 0 & $88,219(85.0)$ & 534.5 & 1,301 & 1.00 & baseline & \\
\hline 1 & $14,750(14.2)$ & 88.9 & 393 & 1.72 & $1.53,1.92$ & $<0.0001$ \\
\hline$\geq 2$ & $769(0.8)$ & 4.5 & 39 & 2.52 & $1.83,3.47$ & $<0.0001$ \\
\hline \multicolumn{7}{|c|}{ Type of relative with breast cancer } \\
\hline Unaffected relative & $88,219(85.0)$ & 534.5 & 1,301 & 1.00 & baseline & \\
\hline Mother only & $11,940(11.5)$ & 71.9 & 295 & 1.72 & $1.51,1.95$ & $<0.0001$ \\
\hline Sister only & $2,730(2.6)$ & 16.5 & 96 & 1.73 & $1.40,2.13$ & $<0.0001$ \\
\hline Daughter only & $80(0.1)$ & 0.5 & 2 & 1.22 & $0.30,4.89$ & 0.78 \\
\hline Combination of relatives ${ }^{\mathrm{a}}$ & $769(0.8)$ & 4.5 & 39 & 2.52 & $1.83,3.47$ & $<0.0001$ \\
\hline \multicolumn{7}{|c|}{ Age of relative at diagnosis(years $)^{b}$} \\
\hline Unaffected relative & $88,219(85.0)$ & 534.5 & 1301 & 1.00 & baseline & \\
\hline$<45$ & $2828(2.8)$ & 16.9 & 97 & 2.47 & $2.01,3.04$ & $<0.0001$ \\
\hline$\geq 45$ & $12,691(12.2)$ & 76.5 & 335 & 1.63 & $1.45,1.84$ & $<0.0001$ \\
\hline
\end{tabular}

$H R$ Hazard Ratio from Cox regression using age as time scale, CI Confidence Interval

* Adjusted for age at menarche, benign breast disease, oral contraceptive use, parity, age at first birth, breastfeeding, age at menopause, hormone replacement therapy use, physical activity, pre- and post-menopausal body mass index, alcohol intake, smoking status, and socioeconomic status

${ }^{\text {a }}$ First-degree female relatives

b Youngest if $>1$ relative with breast cancer

Breast cancer incidence risk in relation to family history has been assessed in published studies by various parameters of the cases of breast cancer occurring in a woman's first-degree relatives $[3,9,11,16,17,22,33,34]$. However, it appears in principle that assessment of familial breast cancer risk should consider not only breast cancers observed in the family, but also the family size and agestructure and hence the expected number of cases if general population rates by age and calendar period prevailed in the family. Such analyses to divide risk by family history score 
Table 4 Likelihood ratio test results comparing Cox-proportional hazards breast cancer risk models for different methods, and combinations of methods, of categorizing family history

\begin{tabular}{|c|c|c|c|}
\hline \multirow[t]{2}{*}{ Model } & \multicolumn{2}{|c|}{$\begin{array}{l}\text { Goodness } \\
\text { of fit }\end{array}$} & \multirow[t]{2}{*}{ Likelihood ratio test ${ }^{\mathrm{b}}\left(\chi_{d f}^{2}\right), P$ value } \\
\hline & $d f$ & $\chi^{2^{*}}$ & \\
\hline (a) Binary family history (Yes/No) & 1 & 94.57 & \\
\hline (b) No. of relatives with breast cancer $(0,1, \geq 2)$ & 2 & 99.29 & \\
\hline (c) Type of relative with breast cancer (No, mother, sister, daughter, combination of relatives) & 4 & 99.55 & \\
\hline (d) Age of relative at breast cancer diagnosis $($ No, $<45$, $\geq 45)$ & 2 & 106.41 & \\
\hline (e) Family History Score (FHS) ${ }^{a}$ & 1 & 102.42 & \\
\hline \multicolumn{4}{|l|}{ Combinations } \\
\hline$(a+e)$ Binary family history added to FHS & 2 & 106.51 & $\chi_{1}^{2}=4.08, P=0.04$ \\
\hline$(e+a)$ FHS added to Binary family history & & & $\chi_{1}^{2}=11.94, P=0.0005$ \\
\hline$(b+e)$ No. of relatives with breast cancer added to FHS & 3 & 110.14 & $\chi_{2}^{2}=7.72, P=0.02$ \\
\hline$(e+b)$ FHS added to No. of relatives with breast cancer & & & $\chi_{1}^{2}=10.86, P=0.001$ \\
\hline$(c+e)$ Type of relative with breast cancer added to FHS & 5 & 112.74 & $\chi_{4}^{2}=10.31, P=0.36$ \\
\hline$(e+c)$ FHS added to Type of relative with breast cancer & & & $\chi_{1}^{2}=13.18, P=0.0003$ \\
\hline$(d+e)$ Age of relative at breast cancer diagnosis added to FHS & 3 & 112.63 & $\chi_{2}^{2}=10.20, P=0.006$ \\
\hline$(e+d)$ FHS added to age of relative at breast cancer diagnosis & & & $\chi_{1}^{2}=6.22, P=0.013$ \\
\hline
\end{tabular}

${ }^{*}$ Variation accounted for by adding variables to model already including age at menarche, benign breast disease, oral contraceptive use, parity, age at first birth, breastfeeding, age at menopause, hormone replacement therapy use, physical activity, pre- and post-menopausal body mass index, alcohol intake, smoking status, and socioeconomic status

a Trend across six groups

b Test of improvement to the fit of the model by addition of alternative method for describing family history

have been undertaken for coronary heart disease and hypertension [26], and breast cancer mortality [27], and for all-cancer incidence in relatives of retinoblastoma patients [35]. To the best of our knowledge, such scores have not been calculated for breast cancer incidence, although one study compared risk in women dichotomized as with or without a family history, allowing for age but not calendar period expectations [36], and family structure has been taken into account when estimating risk of BRCA1 and BRCA2 status [37]. In our analysis using person-years based scores, the FHS discriminated risk more finely than measures based solely on breast cancer occurrence among relatives.

Because it is a continuous variable, the FHS allows for discrimination across the full spectrum of family histories in participants, while conventional discrete variables are confined to two or three categories of risk, with most of those with a positive family history falling into the lowest risk positive family history group (e.g., 393 participants in our study had 1 affected relative but only 39 had $\geq 2$ ). The highest FHS group had a greater relative risk than any of the highest risk groups from conventional categorizations of family history. The majority of participants who had two or more relatives with breast cancer were not in the highest FHS group, but instead fell into other, lower FHS groups, reflecting that multiple affected family members may not indicate a very high risk if a woman comes from a very large family.

The addition of the FHS measure from Table 2 to models based solely on conventional aspects of cases in the family (yes/no; number of affected relatives; type of affected relatives, and age of relative at breast cancer diagnosis, as in Table 3) resulted in significant statistical improvements to the fit of the models. The combination of the age of relative at breast cancer diagnosis and FHS was the best fitted model. Although the age of a relative at breast cancer diagnosis is incorporated in the calculation of the expected number of cases (the denominator) in the FHS, it is not incorporated in the numerator (observed number of cases), unlike the metric of age at relative's diagnosis on its own. Our study had insufficient cases for stable analysis of risk stratified by both FHS and age of relative at breast cancer diagnosis.

As with any observational study, there were some limitations. Reports of family history of breast cancer were provided by participants in questionnaires and were 
unconfirmed, but there is evidence that information from women reporting breast cancer in their first-degree relatives is likely to be highly accurate, with $99 \%$ specificity and $96 \%$ sensitivity reported $[33,38-40]$.

Another limitation was that vital status was only collected for parents in the baseline questionnaire. All sisters and daughters of participants therefore had to be considered alive, and those who had not been diagnosed with breast cancer were censored at the date the participant's recruitment questionnaire was completed. For this reason, some family expected numbers are likely to be slightly overestimated, and subsequently the FHS slightly underestimated. Sensitivity analyses with reduced follow-up time for sisters and daughters, however, showed no material effect on the results.

As stated above, about $28 \%$ of participants had a firstdegree relative who was also a GS participant, but after removing from analyses all participating relatives who joined the GS after the first participating relative (i.e., editing the cohort such that none of the participants are related to each other), results were essentially unchanged.

Most relatives of participants $(70.3 \%)$ were born before 1971. Therefore, estimated incidence rates were used for some calendar years for the majority of relatives when calculating the expected number of family breast cancers, since data on national rates do not exist before 1971 . However, many of the person-years before 1971 were at young ages when breast cancer is uncommon. Thus, any errors consequent on these national rate estimations are likely to have been slight, and anyway non-differential, and therefore unlikely to have influenced the relative risks materially. This applies more so to the estimates of national breast cancer mortality rates before 1911: only 3.8\% of participants' relatives were alive before 1911.

The FHS methodology could potentially be incorporated into risk prediction models for breast cancer, which currently use the number of first-degree relatives with breast cancer [14, 41-46]. The data used to calculate the FHS in first-degree female relatives are easily obtainable from women, making this measure suitable for employment in clinical settings, using a family score algorithm incorporating cancer registration rates. Finally, our modeling of breast cancer risks in relation to the FHS combined with other family history categorizations suggests that the best predictor of risk (if a sufficiently large dataset were available to validate it), might be a combination of FHS and age at diagnosis of breast cancers in relatives.

Acknowledgements We thank Breast Cancer Now and The Institute of Cancer Research for support and funding of the Generations Study, and the study participants, study staff, and the doctors, nurses, and other health-care providers and health information sources who have contributed to the study. We acknowledge NHS funding to the Royal Marsden/ICR NIHR Biomedical Research Centre.
Funding This work was supported by Breast Cancer Now, The Institute of Cancer Research, and a studentship to $\mathrm{H}$ Brewer by Cancer Research UK.

\section{Compliance with ethical standards}

Conflict of interest The authors declare they have no conflict of interest.

Ethical approval The study was approved by the South East MultiCentre Research Ethics Committee and participants provided informed consent.

Open Access This article is distributed under the terms of the Creative Commons Attribution 4.0 International License (http://crea tivecommons.org/licenses/by/4.0/), which permits unrestricted use, distribution, and reproduction in any medium, provided you give appropriate credit to the original author(s) and the source, provide a link to the Creative Commons license, and indicate if changes were made.

\section{References}

1. Torre L, Bray F, Siegel R, Ferlay J, Lortet-tieulent J, Jemal A (2015) Global cancer statistics, 2012. CA Cancer J Clin 65:87-108

2. Barnard M, Boeke C, Tamimi R (2015) Established breast cancer risk factors and risk of intrinsic tumor subtypes. Biochim Biophys Acta Rev Cancer 1856:73-85

3. Hemminki K, Granstrom C, Czene K (2002) Attributable risks for familial breast cancer by proband status and morphology: a nationwide epidemiologic study from Sweden. Int $\mathbf{J}$ Cancer 100:214-219

4. Collaborative Group on Hormonal Factors in Breast Cancer (2001) Familial breast cancer: collaborative reanalysis of individual data from 52 epidemiological studies including 58209 women with breast cancer and 101986 women without the disease. Lancet 358:1389-1399

5. Colditz G, Rosner B, Speizer F (1996) Risk factors for breast cancer according to family history of breast cancer. J Natl Cancer Inst 88:65-71

6. Colditz G, Rosner B (2000) Cumulative risk of breast cancer to age 70 years according to risk factor status: data from the nurses' health study. Am J Epidemiol 152:950-964

7. Colditz G, Rosner B, Chen W, Holmes M, Hankinson S (2004) Risk factors for breast cancer according to estrogen and progesterone receptor status. J Natl Cancer Inst 96:218-228

8. Rosner B, Colditz G, Iglehart J, Hankinson S (2008) Risk prediction models with incomplete data with application to prediction of estrogen receptor-positive breast cancer: prospective data from the nurses' health study. Breast Cancer Res 10:R55

9. Parazzini F, La Vecchia C, Negri E, Franceschi S, Bocciolone L (1992) Menstrual and reproductive factors and breast cancer in women with family history of the disease. Int $\mathrm{J}$ Cancer $51: 677-681$

10. Swerdlow A, De Stavola B, Floderus B, Holm N, Kaprio J, Verkasalo P et al (2002) Risk factors for breast cancer at young ages in twins: an international population-based study. J Natl Cancer Inst 94:1238-1246

11. Figueiredo J, Ennis M, Knight J, McLaughlin J, Hood N, O'Malley $\mathrm{F}$ et al (2007) Influence of young age at diagnosis and family history of breast or ovarian cancer on breast cancer 
oucomes in a population-based study. Breast Cancer Res Treat 105:69-80

12. Chlebowski R, Anderson G, Lane D, Aragaki A, Rohan T, Yasmeen $S$ et al (2007) Predicting risk of breast cancer in postmenopausal women by hormone receptor status. J Natl Cancer Inst 99:1695-1705

13. Tamimi R, Rosner B, Colditz G (2010) Evaluation of a breast cancer risk prediction model expanded to include category of prior benign breast disease lesion. Cancer 116:4944-4953

14. Claus E, Risch N, Thompson W (1991) Genetic analysis of breast cancer in the cancer and steroid hormone study. Am J Hum Genet 48:232-242

15. McCredie M, Paul C, Skegg D, Williams S (1997) Family history and risk of breast cancer in New Zealand. Int $J$ Cancer 73:503-507

16. Anderson H, Bladström A, Olsson H, Möller T (2000) Familial breast and ovarian cancer: a Swedish population-based register study. Am J Epidemiol 152:1154-1163

17. Peto J, Easton D, Matthews F, Ford D, Swerdlow A (1996) Cancer mortality in relatives of women with breast cancer: the OPCS study. Int J Cancer 65:275-283

18. Egan K, Stampfer M, Rosner B, Trichopoulos D, Newcomb P, Trentham-Dietz A et al (1998) Risk factors for breast cancer in women with a breast cancer family history. Cancer Epidemiol Biomarkers Prev 7:359-364

19. Magnusson C, Colditz G, Rosner B, Bergstrom R, Persson I (1998) Association of family history and other risk factors with breast cancer risk (Sweden). Cancer Causes Control 9:259-267

20. Hopper J, Chenevix-Trench G, Jolley D, Dite G, Jenkins M, Ventor D et al (1999) Design and analysis in a population-based case-control-family study of the genetic epidemiology of breast cancer and the co-operative family registry for breast cancer studies (CFRBCS). J Natl Cancer Inst Monogr 26:95-100

21. Ford D, Easton D, Bishop D, Narod S, Goldgar D, Consortium BCL (1994) Risks of cancer in BRCA1-mutation carriers. Lancet 343:692-695

22. Pharoah P, Lipscombe J, Redman K, Day N, Easton D, Ponder B (2000) Familial predisposition to breast cancer in a British population: implications for prevention. Eur J Cancer 36:773-779

23. Jonker M, Jacobi C, Hoogendoorn W, Nagelkerke N, De Bock G, Van Houwelingen J (2003) Modeling familial clustered breast cancer using published data. Cancer Epidemiol Biomarkers Prev 12:1479-1485

24. Tice J, Cummings S, Smith-Bindman R, Ichikawa L, Barlow W, Kerlikowske K (2008) Using clinical factors and mammographic breast density to estimate breast cancer risk: development and validation of a new predictive model. Ann Intern Med 148:337-347

25. Chen J, Pee D, Ayyagari R, Graubard B, Schairer C, Byrne C et al (2006) Projecting absolute invasive breast cancer risk in white women with a model that includes mammographic density. J Natl Cancer Inst 98:1215-1226

26. Hunt S, Williams R, Barlow G (1986) A comparison of positive family history definitions for defining risk of future disease. J Chronic Dis. 39:809-821

27. Yang Q, Khoury M, Rodriguez C, Calle E, Tatham L, Flanders W (1998) Family history score as a predictor of breast cancer mortality: prospective data from the Cancer Prevention Study II, United States, 1982-1991. Am J Epidemiol 147:652-659

28. Swerdlow A, Jones M, Schoemaker M, Hemming J, Thomas D, Williamson J et al (2011) The Breakthrough Generations Study: design of a long-term UK cohort study to investigate breast cancer aetiology. Br J Cancer 105:911-917
29. Cox D (1972) Regression models and life tables. J R Stat Soc Ser B. $34: 187-220$

30. Cowell C, Weigelt B, Sakr R, Ng C, Hicks J, King T et al (2013) Progression from ductal carcinoma in situ to invasive breast cancer: revisited. Mol Oncol 7:859-869

31. Worni M, Akushevich I, Greenup R, Sarma D, Ryser M, Myers E et al (2015) Trends in treatment patterns and outcomes for ductal carcinoma in situ. J Natl Cancer Inst. 107:djv263

32. van Driel C, Oosterwijk J, Meijers-Heijboer E, Van Asperen C, Zeijlmans van Emmichoven I, de Vries J et al (2016) Psychological factors associated with the intention to choose for riskreducing mastectomy in family cancer clinic attendees. The Breast 30:66-72

33. Colditz G, Kaphingst K, Hankinson S, Rosner B (2012) Family history and risk of breast cancer: nurses' Health Study. Breast Cancer Res Treat 133:1097-1104

34. Colditz G, Willett W, Hunter D, Stampfer M, Manson J, Hennekens C et al (1993) Family history, age, and risk of breast cancer. Prospective data from the Nurses' Health Study. J Am Med Assoc 270:338-343

35. Chakraborty R, Weiss K, Majumder P, Strong L, Herson J, Rao D (1984) A method to detect excess risk of disease in structured data: cancer in relatives of retinoblastoma patients. Genet Epidemiol 1:229-244

36. Schildkraut J, Risch N, Thompson W (1989) Evaluating genetic association among ovarian, breast, and endometrial cancer: evidence for a breast/ovarian cancer relationship. Am J Hum Genet 45:521-529

37. Antoniou A, Pharoah P, Smith P, Easton D (2004) The BOADICEA model of genetic susceptibility to breast and ovarian cancer. Br J Cancer 91:1580-1590

38. Mai P, Garceau A, Graubard B, Dunn M, McNeel T, Gonsalves L et al (2011) Confirmation of family cancer history reported in a population-based survey. J Natl Cancer Inst 103:788-797

39. Murff H, Spigel D, Syngal S (2004) Does this patient have a family history of cancer? An evidence-based analysis of the accuracy of family cancer history. JAMA 292:1480-1489

40. Freedman R, Garber J (2011) Family cancer history: healthy skepticism required. J Natl Cancer Inst 103:776-777

41. Gail M, Brinton L, Byar D, Corle D, Green S, Schairer C et al (1989) Projecting individualized probabilities of developing breast cancer for white females who are being examined annually. J Natl Cancer Inst 81:1879-1886

42. Costantino J, Gail M, Pee D, Anderson S, Redmond C, Benichou $\mathrm{J}$ et al (1999) Validation studies for models projecting the risk of invasive and total breast cancer incidence. J Natl Cancer Inst 91:1541-1548

43. Parmigiani G, Berry D, Aguilar O (1998) Determining carrier probabilities for breast cancer-susceptibility genes BRCA1 and BRCA2. Am J Hum Genet 62:145-158

44. Tyrer J, Duffy S, Cuzick J (2004) A breast cancer prediction model incorporating familial and personal risk factors. Stat Med 23:1111-1130

45. Decarli A, Calza S, Masala G, Specchia C, Palli D, Gail M (2006) Gail model for prediction of absolute risk of invasive breast cancer: independent evaluation in the Florence-European Prospective Investigation Into Cancer and Nutrition cohort. J Natl Cancer Inst 98:1686-1693

46. Barlow W, White E, Ballard-Barbash R, Vacek P, Titus-Ernstoff L, Carney P et al (2006) Prospective breast cancer risk prediction model for women undergoing screening mammography. J Natl Cancer Inst 98:1204-1214 